ESCRITAS Vol. 9 n. 2 (2017) ISSN 2238-7188 p. 39-55

\title{
HISTÓRIA DA ÁFRICA ANTIGA PELA ARQUEOLOGIA E HISTÓRIA: PENTEADOS NÍLOTICO-ETÍOPES EM SALA DE AULA
}

\section{HISTORY OF ANCIENT AFRICA BY ARCHEOLOGY AND HISTORY: NICOTIC-ETHIOPIAN HAIRSTYLES IN THE CLASSROOM}

\author{
Maristane de Sousa Rosa Sauimbo ${ }^{1}$ \\ Danielly Morais Rocha
}

\begin{abstract}
RESUMO: Um conflito bem posto aos historiadores contemporâneos e um terreno movediço é abordar a "melano-pigmentação" de povos nilóticos de Norte e Sul na Antiguidade africana. Para além das querelas, nosso artigo aborda o tear dos penteados africanos, pelo viés cultural, para o ensino-aprendizagem de História da África Antiga em sala de aula. Muito mais que paradigmas raciais, este estudo busca comparar técnicas de manipulação dos cabelos entre sociedades dinásticas do Nilo e a sociedade pastoril do povo Afar na moderna Etiópia, considerando os cabelos, como um reflexo dos aspectos materiais da cultura africana que perpassam o passado remoto do continente.
\end{abstract}

PALAVRAS-CHAVE: Arqueologia e história; Estudos africanos; Penteados nilótico/etiópe.

\begin{abstract}
ABSTRATC: A well-placed conflict for contemporary historians and a shaky ground is to encompass the "melano-pigmentation" of Nilotic people of North and South in the African antiquity. In addition to the complaints, our article addresses the loom of African hairstyles by cultural bias for teaching-learning History of Ancient Africa in the classroom. Besides racial paradigms, this study seeks to compare hair manipulation techniques between dynastic societies of the Nile and the pastoral society of the Afar people in modern Ethiopia, considering the hair as a reflection of the materials of the African culture that cross the distant remote continent.
\end{abstract}

KEYWORDS: Archeology and history; African studies; Nilotic/Ethiopian hairstyles.

\footnotetext{
${ }^{1}$ Professora da graduação em História da África da Universidade Estadual da Região Tocantina do Maranhão UEMASUL, Mestre em Gestão do Patrimônio Cultural, Doutoranda em História da África, Faculdade de Letras de Lisboa-FLUL.<maristanerosa@hotmail.com.br>.

${ }^{2}$ Professora da graduação em Arqueologia da Universidade Estadual da Região Tocantina do Maranhão UEMASUL, Mestre em Arqueologia pela Universidade Federal de Sergipe - UFS. $<$ daniellyneai@gmail.com>.
} 


\section{Introdução}

A primeira década do século XX no Brasil é marcada pela aprovação da Lei Federal 11.645/08 que estabeleceu o ensino de História da África, Cultura Afro-Brasileira e Indígena em todos os níveis da educação. Eis que se apresentaram grandes desafios para os Estudos Africanos que durante séculos não fizeram parte do nosso cotidiano escolar.

Ainda em dias atuais, pós-lei, nos deparamos com a nevralgia de conteúdos didáticos e abordagens pedagógicas racializados que precisam de reversibilidade. Assim, concentraremos nossos estudos sobre algumas limitações de abordagens encontradas em sala de aula sobre as sociedades nilóticas da antiguidade que ideologicamente são silenciadas pelo livro didático de História.

Nesse sentido, observa-se que o livro didático não informa sobre os aspectos materiais da cultura dessas sociedades, ignorando fontes tradicionalmente utilizadas, como as arqueológicas e da História Cultural seguindo ainda um modelo cartesiano e pragmático. Logo, como a Arqueologia e a História Cultural poderia oferecer visibilidade a cultura material dessas sociedades que foram higienizados pela cultura da branquitude?

Pela Arqueologia e História iniciam-se os estudos sobre o continente africano, berço da humanidade, que, por meio de diferentes materialidades, dentre artefatos líticos, cerâmicos, edificações, utensílios domésticos e variedade cultural de saberes e fazeres evidenciam de forma singular práticas cotidianas, sociais e culturais de diferentes sociedades. O cabelo, de modo particular, imprime aspectos materiais e indenitários das sociedades pastoris do Chifre da África.

Nosso artigo pretende trazer algumas reflexões de abordagem interdisciplinar e desconstruir o imaginário biologizante, sobre as sociedades antigas do Nilo, Alto e Baixo Egito, Reino do Norte e Sul, Nilo do Norte e Sul, Egito e Núbia, Kemit, Misr, Aegyptus situando a complexidade social e simbólica dos penteados na antiguidade africana como uma linguagem identitária e um viés interpretativo de africanidade.

Essa identidade a partir dos cabelos foi eternizada em pinturas de monumentos funerários no Antigo Egito, e, na contemporaneidade, observa-se que os povos pastoris do oriente africano, também primam pelos penteados como identidade máxima. Entretanto, esses penteados são alegorizados em uma plástica ocidental que difere das características e usos próprios do continente africano. 
Assim, formalizamos uma análise de um vasto acervo imagético digital a partir de fotografias do penteado das sociedades Oromo, da Etiópia de diferentes temporalidades, bem como filmes holywoodianos que massificam e idealizam um Egito ficcional e desafricanizado, dentre os quais, Indiana Jones e os Caçadores da Arca Perdida (1981), Cesár e Cleópatra (1945), Cleópatra (1967) e A Múmia (1999).

Como aporte teórico-metodológico utilizamos a análise da tese de Tassei (2008), Fletcher (1995) e o artigo de Candeias (2007) sobre a plástica e estética dos Egípcios, Núbios e Etíopes, exemplificando como essa estética permitiu o surgimento de uma abordagem para História da África pela ótica da Arqueologia e História e pela materialidade do campo visual.

\section{Antiguidade Africana para além de Hollywood}

Amiúde, as notícias televisivas e web-sites, jornais eletrônicos destacam, sem muita propriedade, informações arqueológicas e históricas sobre descobertas do Antigo Egito. Ora é a tumba de um faraó, uma múmia inédita, um túmulo, riquezas em ouro, etecetera. Sem dúvida o assunto é vendável, povoa o imaginário popular e sempre colocou muitas dúvidas ao pensamento europeu, de Homero e Heródoto até nossos dias. O tema obsesionou particularmente os negros estudiosos norte-americanos, depois africanos dos anos de 1950 (M'BOKOLO, 2003, p. 62).

Por outro lado, os estudos de História Antiga, raramente contemplam o continente africano. Quando o fazem, não revelam sociedades indígenas que conviveram plenamente com as formações estatais. Isto é comumente observável na História da Antiguidade do Oriente Próximo e nela a História de Kemit, Misr, Aegyptus. O Egito, apesar de ser consensual a sua localização no continente africano, pelos mapas e referências geo-culturais, o mesmo, muitas vezes é revelado como se fizesse parte de um mundo mediterrânico, mesopotâmico não especificado (LIMA, 2006).

Esse tipo de comentário se encaixa bem com a representação de filmes como "Indiana Jones" (1981), no qual, o arqueólogo Indiano Jones precisa encontrar a Arca da Aliança, uma relíquia bíblica que contém os dez mandamentos, cujo enfoque mesmo ficcional não privilegia a ligação com terras africanas ao Sul onde ficam hoje a Etiópia e o Sudão.

Desse modo, nos campos que configuram a cultura visual, pelo cinema, revistas e web-sites, as formas de "raças" mantem-se atualizadas. Trazemos aqui para exemplificar o 
filme "César e Cleopatra" de 1945 e "Cleópatra" de 1967, ambos no estereótipo hollywoodiano.

O filme de Cleópatra, estrelado por Elizabeth Taylor cristalizou o penteado e as perucas egípcias em um modelo europeizado (Figura 1). O cabelo e as perucas são representados em um padrão liso e comportado e adequado socialmente, contrapondo com o africano carapinha ${ }^{3}$ e inadequado socialmente.

Por outro lado, é importante destacar que os mesmos filmes incorrem a contradição ao utilizarem nas perucas ficcionais o misto liso e crespo através do uso de trançados discretos que não revelam a originalidade do penteado, omitindo assim, a materialidade do cabelo carapina do Egito Antigo (Figura 2) não legitimando o cabelo africano em genuinidade. Esse perfil também pode ser exemplificado no filme "A Múmia" (1999) que destaca os trançados da rainha Anck-su-Namun.

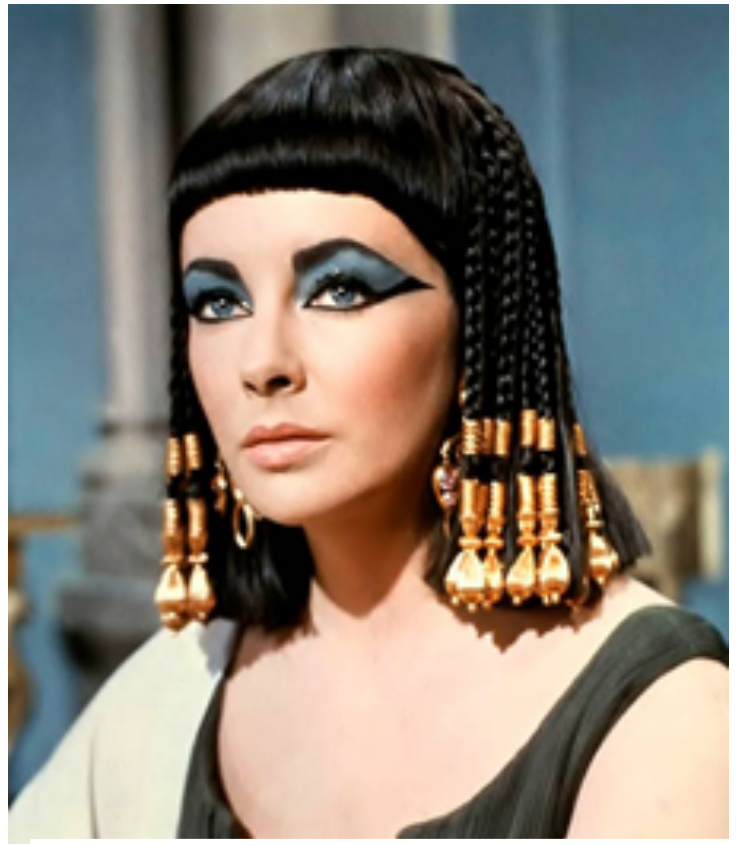

تig. 1 - Cleópatra, Elizabeth Taylor. onte: MANKIEWICZ, 1967.

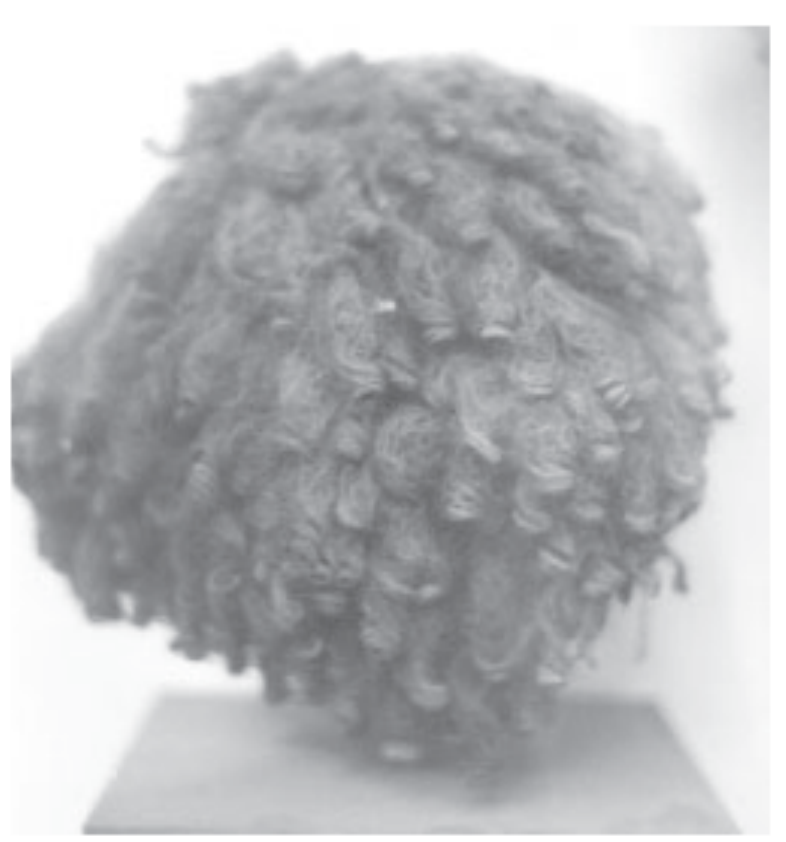

Fig. 2 -.Peruca de Istemkheb, 21 ${ }^{\mathrm{a}}$ Dinastia. Museu do Cairo onte: FLETCHER, 2015.

\footnotetext{
${ }^{3}$ Cabelo crespo não liso, estilo "afro".
} 
Geoffrey John Tassie (2008), arqueólogo especialista em penteados egípcios, atesta o uso dreadlocks ${ }^{4}$ na XII Dinastia, representado na estátua real de Amenemhet III que evidencia um dos cabelos característicos dessas sociedades.

This hairstyle is first attested on a statue of a king found at Hierakonpolis. The only other kown statue with this hairstyle is on one depicting king Amenemhet III of Dinasty XII, therefore it can be said to be worn only by kings. These hairstyles consists of layers of matted (dreadlocks) locks, with are thick at the root and twisted at the ends. The overall effect of this hairstyle is a large and bouffant (TASSEI, 2008, p. 416).

Assim, a beleza plástica dos egípcios foi assunto que empolgou viajantes e estudiosos de todos os tempos. Heródoto no século V a. C., por exemplo, faz uma série de elogios a estética do Nilo em um contexto completamente desrracializado, demostrando a africanidade do penteado e admitindo a estética vinculada ao modelo econômico, as culturas de pastoreio, agrícola e fauna nesse período.

Heródoto descreveu os colchians, egípcios e etíopes pretos com cabelos de ovelha, cachos de lã, ora chamados de tranças, crespos, enrolados. Considerava tais povos como os únicos mais antigos que praticavam a circuncisão: "Os etíopes são, ao que parece, os homens mais altos e mais belos do mundo" (apud M'BOKOLO, 2003, p. 82).

Em 1787 destaca-se, precisamente na obra do historiador francês Volney, Voyage en Egypte et en Syrie, a resposta para o grande enigma dos povos tão admirados na Europa no final do século XVIII.

O referido autor acreditava ter a resposta sobre a aparência dos egípcios e sua melano-pigmentação, para o qual eram negros por serem queimados do sol. Entretanto, durante uma visita ao Egito, mudou de ideia declarando espanto diante da esfinge, comparando a cabeça do monumento, como semelhante à de um legítimo africano nativo, destacando o rosto, olhos, nariz e boca (VOLNEY, 1825 apud M'BOKOLO, 2013, p. 61).

A partir desses elementos, observa-se que a cabeça está sempre em evidência, sendo considerada uma das identidades em comum entre os distintos povos africanos em diferentes temporalidades. Ela simboliza força vital tendo nos cabelos um elemento forte de identidade.

\footnotetext{
Segundo Platão, a cabeça humana é a imagem do mundo. Nos símbolos dos hieróglifos no antigo Egito, a cabeça significa céu, em virtude do seu desenho circular. Até hoje a cabeça representa o lugar mais sagrado do corpo em todos os povos e culturas do mundo (LODY, 2004, p.14).
}

\footnotetext{
${ }^{4}$ Designação em língua inglesa para o cabelo enrolado em formato de pavio, modelado com cera de abelha. Comumente está associado ao movimento Rastafari.
} 
Achados arqueológicos dão conta do modelo de peruca, já descrita por Heródoto, hoje exposta no Museu Egípcio do Cairo. É uma peruca em estilo “duplex”, distinguida em duas sessões, uma de cachos de lã de ovelha e a outra de tranças de cabelo humano (Figura 3), datada do século XIV a. C., típica para oficiais do sexo masculino (FLETCHER, 1995).

A peruca duplex, de Ahmose-Hentempet da $18^{\mathrm{a}}$ Dinastia (Figura 4) possuía modelo curto e arredondado na parte superior, anexada nas costas por tranças longas e finas, contendo cera de abelha para fixação do penteado e coberta de gordura animal. A peruca foi encontrada no túmulo de um sumo sacerdote de Amon, Tebas, onde hoje é a moderna Luxor (FLETCHER, 1995).

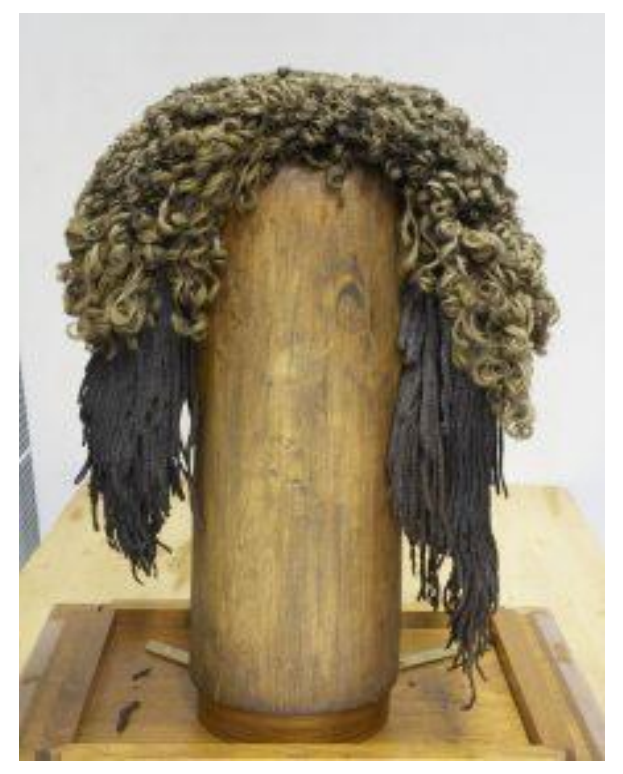

Fig. 3 - Peruca duplex masculina, 14001300 a. C. Deir el-Medina. Fonte: FLETCHER, 2015.

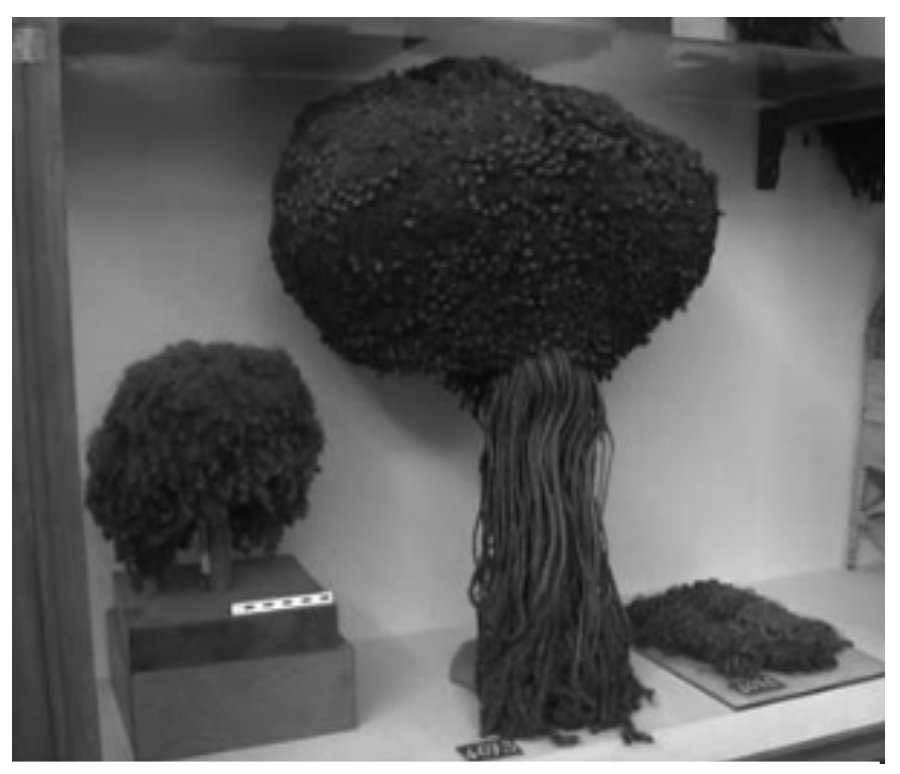

Fig. 4 - Peruca duplex (à direita) Ahmose-Hentempet. Museu do Cairo.

Fonte: FLETCHER, 2015.

Entre as substâncias analisadas para fixação ou hidratação do cabelo encontram-se cera de abelha, esterco bovino e óleos de gordura animal. As perucas necessariamente eram decoradas com ouro, penas, fitas e usadas em ocasiões solenes. Os penteados auxiliam-nos em estudos sociais, culturais e religiosos do Antigo, Médio e Novo Império (FLETCHER, 1995).

De acordo com Fletcher (1995, p. 39) é seguro afirmar que em sociedades indígenas e pastoris da atualidade na África Oriental, Sudão, Quênia e Etiópia, as técnicas de manipulação do cabelo em muito se assemelham as técnicas do passado identificadas a partir de escavações arqueológicas, como o uso da cera de abelha para fixar o cabelo dreadlooks e a manteiga bovina que hidrata, embeleza, ao mesmo tempo em que demonstra status social. 
Os estudos de Tassie (2008) ao investigar os cabelos na antiguidade africana, apontam a contribuição dessa materialidade para uma análise das relações cotidianas nas sociedades nilóticas, como, a distinção das categorias sociais, status econômico e político e até mesmo a presença de ritos iniciáticos.

A arqueologia descobriu ainda espelhos, grampos de cabelo, recipientes de maquiagem e pentes de marfim, vestígios materiais que apontam o cuidado com a beleza, a aparência, a estética que os acompanhava até o túmulo, indicando que eles queriam ficar belos na vida após a morte.

A Antiguidade africana nilótica é heterogênea, pluricultural. Percebemos a marca do continente desde as primeiras formações estatais africanas compreendidas pela diversidade. Em todo o circuito do vale do Nilo, dezenas de povos, culturas e formas de expressão e identidades dialogaram entre si substancialmente no contexto africano, por vezes similaridades existentes entre si. Os povos pastoris da atual África Oriental foram contemporâneos de Egípcios, Núbios, Axumitas, parentesco apresentado pelos estudos arqueológicos e históricos, a partir da cultura material dos penteados da cabeça.

O povo Afar guarda ainda hoje distinção de status social, gênero e idade, saberes e fazeres através das técnicas de manipulação e cuidado dos cabelos. Durante milênios o uso de cera de abelha e leite bovino, esterco de gado, mantém-se preservados nessa sociedade. A técnica é favorável ao estudo dos penteados usados no antigo vale do Nilo.

Diodoro da Sicília que realizou viagem ao Egito nos anos 60-56 a. C., nos seus escritos referiu que os costumes dos colonos egípcios eram na maior parte etíopes, dos quais conservaram antigas técnicas. Tanto Diodoro quanto Heródoto, ambos consideraram que entre etíopes e egípcios houve uma mesma beleza plástica no arranjo capilar e nos adereços de cabeça como "bonés de feltro". Foram dois povos exímios na tessitura dos cabelos. O primeiro, Diodoro também elencou que além dos “cabelos crespos dos egípcios” por vezes adornados em semelhança, possuíam a mesma organização:

[...] são feitas purificações por todos quantos estão encarregados dos cultos dos deuses, estão barbeados da mesma maneira, e usam o mesmo vestuário e o tipo de ceptro em forma de charrua, que possuem também os reis, que trazem altos bonés de feltro, sendo o alto acabado em bossa e cercados voltas de serpente que eles chamam áspide (apud M'BOKOLO, 2003, p. 56).

Os cabelos texturizados do Antigo Egito e Núbia pintados em necrópoles, nos achados arqueológicos, pela materialidade das perucas, demonstram técnicas e estética nos seus penteados que podem ser compreendidos pela cultura Afar, povos etíopes da atualidade 
que habitam o Oriente africano, na forma como esses lidam com o cabelo da cabeça, utilizando também cera de abelha, leite bovino, esterco de gado, uso de fitas, penas de aves.

$\mathrm{Na}$ obra Egypte ancienne, Jacques-Josef Champolion-Figeac (1830 apud M'BOKOLO, 2013, p. 59), descreveu o cabelo crespo dos egípcios como semelhante em beleza às nações melhor constituídas da Europa e Ásia ocidental. Estudou largamente as numerosas iconografias egípcias e nos princípios do século XIX nos deu descrições dizendo que:

No vale propriamente dito de Biban el-Mulok (Tebas oeste), admiramos, como todos os viajantes que nos precederam, a surpreendente frescura e a finura das esculturas de vários túmulos. Mandei desenhar a série de povos figurando em baixorelevo. [...] longa cabeleira entrançada (M'BOKOLO, 2013, p. 59).

Os egípcios em suas pinturas, esculturas e baixos-relevos eram obsessivos em abreviar os traços da longevidade (rugas, flacidez, calvície) através de ilustrações idealizadas como forma de amenizar o peso da idade. Contrariando os escritos, homens e mulheres assumiam o papel figurativo da "jovialidade em negação da velhice", como forma de alcançar a vida extraterrena nos moldes ilustrados (CANDEIAS, 2015).

Algumas ilustrações funerárias do antigo Egito, "lidaram plasticamente com as figurações do corpo e noção de tempo", representando-se de forma idealizada através da "lei da estereotipação das imagens" (CANDEIAS, 2015). O túmulo de Arinefer e de Pachedu, ambos da $19^{\text {a }}$ Dinastia, situado em Deir el-Medina, apresenta o casal com face jovial e pele viscosa numa contraposição aos cabelos grisalhos, assinalando que marcas da idade são paradoxalmente anuladas pela juventude; uma imagem idealizada, e não real, cujas feições físicas não condizem com o detalhe dos cabelos embranquecidos alterados pela idade.

O tratamento estético dado ao corpo em vida era o mesmo destinado aos mortos, cuja mumificação física garantia uma vida eterna pós-morte. Os cuidados com o corpo exigiam um embelezamento estético que imitasse a vida, para isso incluíam banho ao corpo, tratamento com óleos e perfumes, incorporação de joias e adereços, como forma de assegurar sua sobrevivência em condições materiais e simbólicas privilegiadas na eternidade.

Sennefer, um governador tebano da $18^{\mathrm{a}}$ Dinastia, "administrador de celeiros e gados", alto dignitário da corte egípcia no século XV a. C., tumba conhecida como "túmulo das vinhas", é um exemplo de prestígio econômico eternizado.

A cosmovisão como ligação e/ou fixação à outra vida, representa-se pelos penteados homenageando a agricultura, a colheita, o pastoreio. 
Os cabelos da cabeça trançados em formado de gavinha ${ }^{5}$ representam "O poder mágico reside em objetos que estão ligados aos indivíduos em situações rituais - por exemplo o sangue, o cabelo, unhas cortadas, etecetera, de pessoas envolvidas com rites de passage" (FRAZER, 1918 apud LEACH, 1997, p. 166).

A tessitura dos cabelos ricamente penteados, desenhados nas necrópoles, garantiam força necessária para "agarrar-se" na eternidade. Analogamente, a gavinha das uvas simbolizam para os egípcios a existência humana bifurcada na passagem da vida para morte, do nascer para o morrer.

No templo de Karnak em finais do reinado de Tutmés IV e início do reinado de Amenhotep III encontram-se cenas do escriba Nakht, "chefe do gado", "responsável dos vinhedos reais", executando tarefas agrícolas, de horticultura e de vinicultura. Nakht em companhia da esposa, filhos e filhas, apresenta-se com corpo jovem e perfeito, vigoroso e bem constituído, acompanhada ainda por jovens com elegantes vestidos de linho, adornada com delicados enfeites e lindas cabeleiras destinados a acentuar graciosidade, elegância e beleza.

O gado visto como elemento indispensável na economia egípcia, ora como profissão e/ou afirmação de status social, dele também extraiam dentre outras coisas, matéria prima para confeccionar produtos destinados à hidratação e preservação das "lindas cabeleiras" (CANDEIAS, 2015).

$\mathrm{Na}$ Etiópia grupos culturais de criadores de gado tradicionais, fazem da manteiga do gado o ingrediente adequado para compor seus padrões de beleza e o design de suas cabeleiras.

Os Afar, Karrayyu, Bofana e Hamer utilizam como princípio ativo o leite bovino, para seus penteados mais elaborados. Visto desta maneira, essas comunidades contemporâneas da Etiópia não diferem dos egípcios no que toca aos cuidados cosméticos dos cabelos, pois é do leite do gado que produzem a manteiga adequada para nutri-los contra os raios solares.

\footnotetext{
${ }^{5}$ Conforme dicionário é um órgão de fixação das plantas das plantas sarmentosas ou trepadeiras e que com elas se prendem a outras e/ou estacas. $\mathrm{O}$ mesmo que garra.
} 


\title{
Povos Pastoris: Estética Nilótica-Etíope
}

O escritor e geógrafo árabe Ibn Sa'id escreveu sobre o "Danakil" povo Afar no século XIII. Outros registros históricos mencionam os Afar na corte do imperador etíope Amda Seyon, no século XIV e também sob o governo de Baeda Maryam (LEWIS, 1995).

Franchetti (apud LEWIS, 1995) sugere que o povo Afar são o mítico bíblico Ofir, descrito por imigrantes árabes sobre a tradição da Abissínia. “Ofir, Havilá e Jobabe. Todos esses descenderam de Joctã. E habitavam uma região que se estendia desde Messa até Sefar, nas colinas do leste do Oriente" (GÊNESIS, 10:29-30).

A linguagem e cultura dos Afar estão diretamente relacionadas aos Oromo. Povo nômade, criadores de gado, de língua cuxita (afroasiática), que residem principalmente no Chifre da África, na Etiópia, Eritréia e Djibouti.

\begin{abstract}
A cultura oromo caracteriza-se por múltiplos traços específicos, entre outros pela relação estreita entre o homem e os animais já mencionada. O gado era não apenas seu principal meio de existência, mas também objeto de suas preocupações de ordem emotiva e ritual. Esse culto do gado, com seu lado moral, impregnava toda essa cultura, a ponto de a carga emocional da atividade agrícola ficar comparavelmente insignificante. Esse fenômeno tem suas raízes no próprio mito da criação, pois, ao criar os homens, Deus exclamou: "Eh, kota, abba loni! ” (Aparecei, senhores do gado!) (HABERLAND, 2010, p. 847).
\end{abstract}

Os grupos étnicos etíopes Afar Karrayyu, Bofana e Hamer, dedicam-se muito à estética dos cabelos, tendo-os como elemento identitário. Comumente usam manteiga para modelar seus cabelos, criando ondulações elaboradas. A representação dos penteados revelam masculinidade e feminilidade, seu pertencimento clãnico e diversos papéis sociais desempenhados na ordem política, econômica e religiosa.

Os diferentes penteados são usados para indicar uma série de distinções de status, os diferentes graus de estratificação $G a d a^{6}$ : virgens e mulheres casadas, meninos, mulheres e homens, nobreza e plebeus, indivíduos insiders e outsiders.

O status do guerreiro é indicado pelo cabelo pintado de manteiga (Hadiyya), em vermelho ocre (Sidamo) ou usando penas de avestruz no cabelo (Somali). Entre os Amhara o status de guerreiro (shifta) é indicado por um cabelo selvagem e espesso. Entre os Dorze, as mulheres dos líderes da assembléia são conhecidas por usarem o cabelo trançado sobre a testa,

\footnotetext{
${ }^{6}$ É um sistema tradicional de estratificação social indígena do povo Oromo, na Etiópia, desenvolvido a partir do conhecimento adquirido ao longo de gerações. Ele regula a atividade política, econômica, social e religiosa servindo como mecanismo para fazer cumprir a conduta moral, fortalecer a coesão da comunidade e expressar a cultura. Foi inscrito pela UNESCO como Patrimônio Cultural Imaterial da Humanidade.
} 
formando uma espécie de escudo na testa. Entre o povo Gurage, "homens pobres" tinham a cabeça completamente raspada; os homens "comuns" usavam pequenas tranças na parte de trás ou uma trança na parte central da cabeça; idosos e "homens ricos" usavam os cabelos crescidos (LEVINE, 1974).

O grupo Afar destaca-se pelo estilo chamado “dayta” (Figura 5), coberto com leite coalhado, tom esbranquiçado. O cabelo é enrolado em espiral com uma fina vareta, uma espécie de pente de madeira decorados com escultura é usado por ambos os sexos sendo usados como ornamentos nos cabelos. O modelo "asdago" (Figura 6) compreende o formato da copa de uma árvore, bem arredondado e adquire tom embranquecido devido o leite.

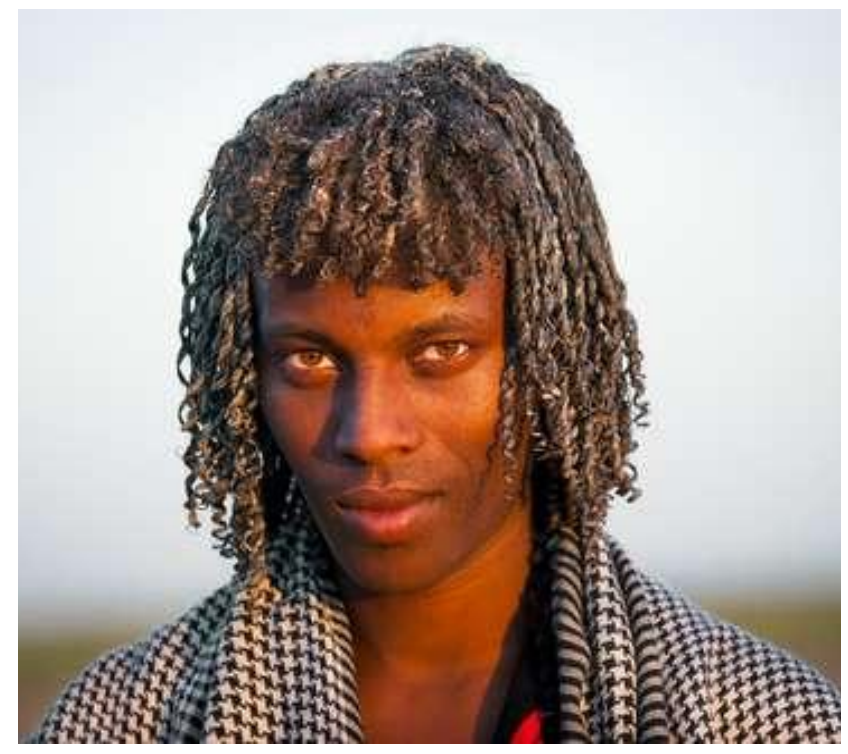

Fig.5 - Cabelo aAfar "dayta"

Fonte: BRIDGE, Sarah; STYLES, Ruth (2014).

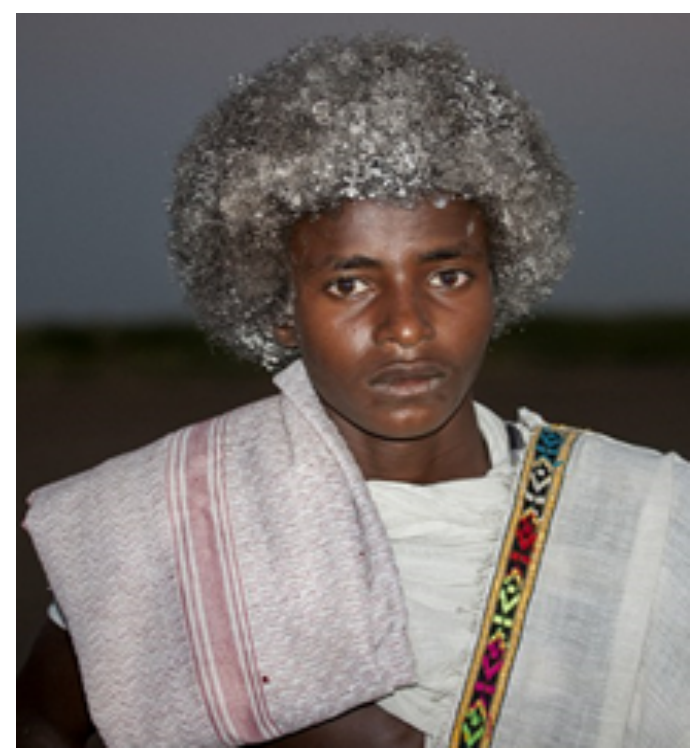

Fig. 6 - Cabelo Afar "asdago"

Fonte: BRIDGE, Sarah; STYLES, Ruth (2014).

Já os Karrayyu possuem um penteado chamado "gunfura" (Figura 7). O cabelo é moldado no formato de copa de árvore. Na parte da testa adquire um formato fálico, pontiagudo, triangular, a cabeça como "potência sexual". Entre os Karayyu, seus "cabelos orgânicos", untados com esterco, destacam-se pela modelagem "unha do gado", fita em volta da cabeça, uma pena de avestruz, usada no cabelo por guerreiros para denotar uma caça bemsucedida. Quando casado, o homem faz um furo no centro do cabelo e preenche com manteiga logo ao amanhecer. Ao longo do dia a manteiga derrete, escorrendo pelas costas sendo aceito completamente como substância mágica, conotação sexual consciente. O cabelo da cabeça como um símbolo: "sêmen” (LEACH, 1983, p. 158). 
o comportamento do cabelo abrange um conjunto ritualmente compreendido, de simbolizações sexuais conscientes que ele desempenha um papel tão importante em rituais do tipo rites de passage que envolvem a transferência formal de um indivíduo de um status sócio-sexual a outro (LEACH, 1983, p. 158).

No caso do Egito, Osíris é uma deidade nilótica, identificado como deus de vida após a morte, da transição, ressurreição e regeneração (Figura 8). Também é o deus da guerra e da fertilidade. Classicamente é retratado usando uma fita/coroa, com uma pena de avestruz na cabeça (WILKINSON, 2003). A cabeça de Osíris como sagrada e mágica, potente em si mesma, representando associações simbólicas ao sobrenatural.

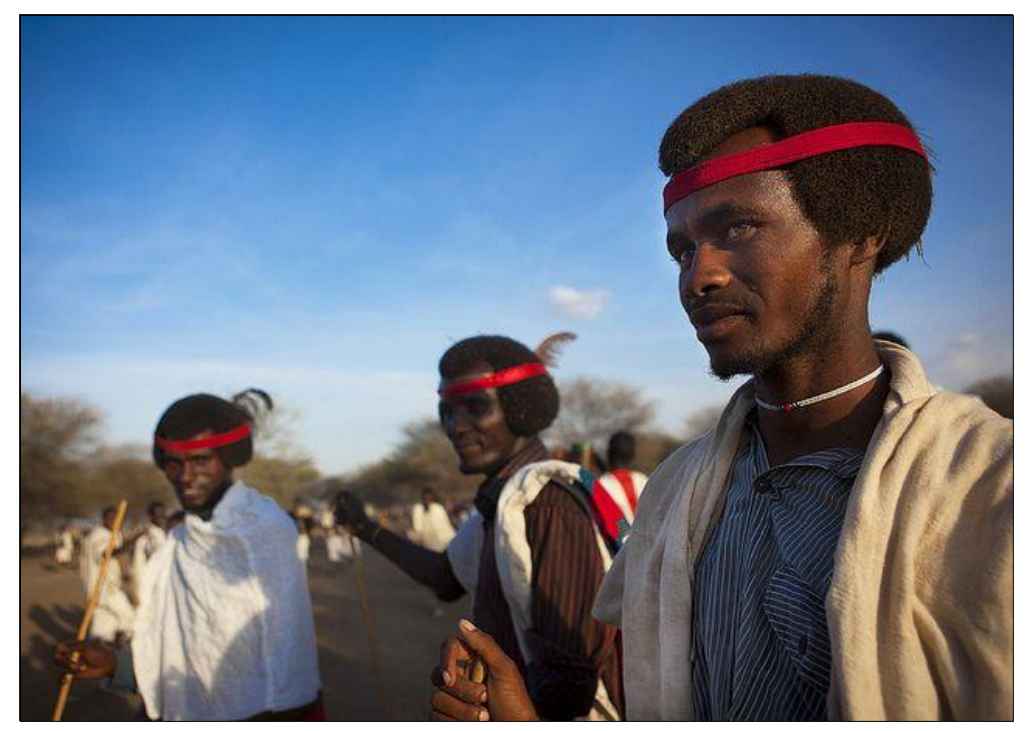

Fig. 7 - Cabelo Karrayyu "gunfura"

Fonte: BRIDGE, Sarah; STYLES, Ruth (2014).

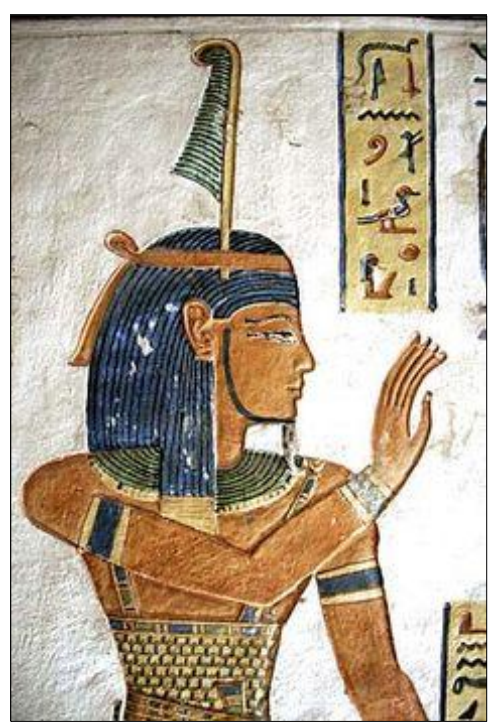

Fig. 8 - Osíris, Deus da guerra e da fertilidade.

Fonte: British Museum (1992).

Analogamente, os Karrayyu e Osíris tem em comum a cabeça adornada com pena de avestruz, como símbolo de masculinidade, fertilidade, força e poder de guerra.

E, de acordo com a literatura de Stith Thompson's Motif Index of Folk Literature (1955-1958), acrescenta que o cabelo tanto na cabeça quanto no corpo pode ser associado a forças sobrenaturais. A dedicação aos cabelos é uma ligação ao mundo sagrado, especialmente a uma divindade, tornando o indivíduo um parente de forças etéreas.

Seguramente a cabeça dos Karrayyu e Osíris possui representação sexual, potência mágica, efeito mágico, vinculado ao indivíduo e à sua categoria. A cosmogonia e mitos fundadores estão vinculados à estética da cabeça nas sociedades africanas.

Um aspecto que consideramos para nosso estudo é a etnografia dos cabelos da cabeça na África etíope, seu funcionamento por estruturas rituais duais como "nascimento e 
morte, sagrado e profano, união e separação, puberdade e maturidade" (SYNNOTT, 1987, p. 381-413). O cabelo da cabeça como status social, distinção étnica, ritos iniciáticos, poderes mágicos e força. O uso de produtos especiais, elixir lácteo para untar e condicioná-lo, veste-o como assento da alma, personalidade individual e coletiva onde ele cresce.

É uma verdade que o cabelo representa um ato simbólico, um ritual de comunicação pública, de distinção na estrutura social na estrutura social da comunidade. A etnografia de G. A. Wilken (1886) pressupõe que o cabelo é um símbolo universal e E. Crawley (1927 apud LEACH, 1983, p. 144) evidencia que "a cabeça é o assento da alma".

Os adornos de cabeça, feitos com pelo e couro de animais, fibras naturais trançadas e penas de aves, recebem um tratamento estético minucioso. Os penteados integravam, e ainda hoje integram os modelos de beleza dos povos do gado na África.

A tradição nos diz que o Oromo arrisca a vida em lugares selvagens em busca de cobiçados troféus. O guerreiro por exemplo, tem direito a certos privilégios, tais como o porte de enfeites reservados aos caçadores: penteado untado de manteiga e ornamento fálico sobre a fronte. Uma peça da caça, o pelo, pele, dentes, unhas, transformados em brincos, colares e adornos de cabeça conferiam ao guerreiro uma posição de prestígio na comunidade.

O dinamismo militar como elemento da identidade dessas sociedades, prescreve ao menos uma expedição guerreira no decorrer dos oito anos da classe dirigente. $\mathrm{O}$ ideal de herói como caçador bem sucessivo é comum a todos os povos do Nordeste da África.

A bravura, também está associada aos penteados, modos de embelezamento definindo status social. Por exemplo, a partir do leite pasteurizado modelam o cabelo em espiral, no formato da copa de árvore, rotineiramente dedicando ao pastoreio a sua arte dos cabelos da cabeça como símbolo de prosperidade e fertilidade.

A partir dessas perspectivas nota-se que nunca se leu nenhum argumento análogo em favor do antigo pensamento egípcio na África contemporânea. Appiah (1997, p. 148) acrescenta que "as transformações por que passaram os mundos conceituais da África e da Europa, desde, respectivamente, o século V a. C. e a $18^{\mathrm{a}}$ dinastia, são tão grandes, e nossas formas de vida são tão diferentes, que o nível de compreensão vislumbrável pela pesquisa histórica é certamente muito limitado."

O literato senegalês Cheik Anta Diop defendeu com o máximo vigor, em The African Origins of Civilisation, que a antiga filosofia egípcia foi importante para a vida intelectual africana contemporânea. No entanto, se os "egipcianistas", como chama Appiah a Diop, se eles estiverem certos, "o Egito antigo merece um lugar mais central do que lhe é 
atualmente conferido no estudo do pensamento antigo: e, se têm razão, ele deve ser estudado na África, na Europa, na América e na Australásia, onde quer que haja um interesse pelo Mundo Antigo" (APPIAH, 1997, p. 148).

Vejamos que foram nos anos de 1950, que cientistas negros norte-americanos, seguidos de africanos instauraram uma acirrada relação de forças estabelecidas com europeus pelo debate racial em torno do Egito faraônico. O colóquio no Cairo em 1974 suscitou o debate sobre o "povoamento do Egito antigo e a decifração da escrita meró́tica" acirrando a insistência dos partidários do povoamento "branco" e na outra extremidade os que defendiam um povoamento "negro", como Cheik Anta Diop e Theóphile Obenga (1974 apud M'BOKOLO, 2003, p. 63). Dentre os mais expressivos pensamentos de todo período, Diop destacou-se debatendo em desfavor do racismo adversário, mas por outro lado recuperou o conceito de "raça" e "civilização", tão tenaz quanto o outro postulado fundamental da corrente opositora. Revisitando o pensamento revolucionário chiekantiano mesmo cristalizado em aspectos característicos do racialismo, é impossível não reconhecer nele o incentivo para que historiadores da África incluíssem o tema tabu "Egito" em seu rol de conteúdos, o que ele chamou de superação ao "the African historian who evades the problem of Egypt" (DIOP, 1974).

Appiah (1997) nos diz que seria lamentável que o chouvinismo de intelectuais europeus, norte-americanos ou australasianos seja demasiado para aceitar isso, e, procedendo desta maneira, é possível que tais assuntos estivessem confinados a serem estudados na África ou no seio de movimentos militantes.

\section{Considerações Finais}

A fabricação da categoria "negro", em singular, perpassa os discursos das mais diversas ordens sociais, do científico ao senso comum. Perpassam discursos de diferentes orientações ideológicas, desde os mais conservadores aos mais progressistas, incluídos aqueles produzidos pelo movimento negro norte-americano, caribenho e brasileiro.

Tais discursos distinguem pela divergência o suficiente para configurar, no terreno em que encontram e se atritam umas das polêmicas mais importantes ainda neste século, "a raça".

A identidade do negro, baseada em características biológicas, na celebração da cor da pele e na textura do cabelo, no elogio exagerado a ela associadas, acaba por definir o negro 
a partir de características biológicas e atitudes a ela associadas. Este trabalho se presta a ser "visceralmente oposto a todas as formas de opressão", ou seja, no caso do negro, contra estereótipos que fixam arquétipos contendo elementos altamente negativos bem como outros positivos.

Pensamos a Lei 11.645/08 como uma medida legal de combate da condição racial reconhecida como fator estruturante na realidade educacional brasileira, nosso estudo evidencia abordagens arqueo-históricas no sentido de que o ensino-aprendizagem possa equilibrar a evidência da diferenciação racial.

Nesta concepção "raça" é uma afirmação para exclusões: é um sistema classificatório aberto, atuante que está internalizado na educação brasileira e em relação ao qual o presente artigo desenvolve a abordagem da cultura material de povos indígenas contemporâneos do Oriente Africano, sendo esta, uma abordagem internalizada que contribui para eficácia dos Estudos Africanos.

Convém elucidar que os universos culturais nesse estudo não apreenderam os espaços sociais de forma mumificada, como no longínquo passado núbio e egípcio e com as sociedades etíopes atuais. As características similares da cultura, aqui registradas, serviram apenas para discorrer sobre estruturas, por vezes abstratas, equivalentes em espaços sociais africanos. As "estruturas" apenas ancoram a metodologia para estudo dos egípcios, núbios e etíopes todos tão correlatos pela utilização sagrada do cabelo como signo de fortalecimento identitário.

A experiência cultural do mundo ocidentalizado quando desvincula o continente africano impede que o conhecimento se torne práxis. A verdadeira prática científica deve remeter à conversão do pensamento, a revolução do olhar, a ruptura com o pré-construído na ordem social.

Parece-nos que a história estruturante quis desintegrar o espaço africano, ao passo que os estudos pela arqueo-história desperta dessa sonolência para reassumir a temporalidade dos acontecimentos das culturas transnacionais, passando a reivindicar e construir identidades de memórias conectadas do presente com o passado a partir de imagens reconstruídas.

Por isso nosso estudo investigou a pluralidade do contexto social dos penteados africanos, revisitados a partir do cinema, do livro didático e de websites, reorganizando-os e ressignificando-os no cotidiano escolar.

Acreditamos que a discussão exposta não se esgota, a constatação de uma plurietnicidade dos cabelos da cabeça pode ser considerada um laboratório cheio de 
indicativos para a construção de alternativas para sofisticar os conteúdos didáticos em sala de aula, que há séculos distanciam grupos africanos uns dos outros.

Oxalá que uma abordagem cultural de conteúdos em História da África, se torne práxis de ações históricas no cenário sócio educacional brasileiro para minimizar a segregação visível no ensino-aprendizagem.

Concluímos que a nossa pesquisa não incorre em analise essencializante, mas nos elementos cultuais ou a cosmovisão do penteado culturalmente associados às sociedades africanas.

\section{REFERÊNCIAS}

APPIAH, Kwame Anthony. Na casa de meu pai: a África na filosofia da cultura. Rio de Janeiro: Contraponto, 1997.

BRIDGE, Sarah; STYLES, Ruth. The Ethiopian tribes who use BUTTER to style their hair: Incredible photos reveal the elaborate curled creations of the Afar people, and the Hamer who mix ghee with red ochre to spectacular effect. Daily Mail, 12 February 2014. England, 2014 [online]. Disponível em: <http:/www.dailymail.co.uk/femail/article-2555821/The-Ethiopiantribes-use-BUTTER-style-hair-Incredible-photos-reveal-elaboratecurled-styles-Afar-peopleHamer-mix-ghee-red-ochre-spectacular-effect.html>. Acessado em: 13 mar. 2014.

CLEÓPATRA, César e. Direção: Gabriel Pascal. Reino Unido, 1945. 138 min. Son, Color.

CLEÓPATRA. Direção: Joseph Mankiewicz. Estados Unidos, 1963. 243 min. Son. Color.

FLETCHER, Amy Joann. Ancient Egyptian Hair: a Study in Style, Form and Function. 1995. Thesis (Doctoral in Archeological) - Faculty of Arts, University of Manchester, Manchester, 1995.

HABERLAND, E. O chifre da África. Brasília: UNESCO, 2010.

KI-ZERBO, Joseph. História da África Negra. Portugal: Europa-América, 1999.

LEACH, Edmond Ronald. Antropologia. São Paulo: Ática, 1983.

Cabello mágico. Alteridades. México, v. 7, n. 13, pp. 91-107, 1997 [online]. Disponível em: < http://www.redalyc.org/pdf/747/74711130012.pdf>. Acessado em: 26 ago. 2015.

LEVINE, Donald N. Greater Ethiopia: The Evolution of a Multiethnic Society. Chicago: The University of Chicago, 1974.

LEWIS, I. M. Peoples of the Horn of Africa (Somali, Afar and Saho): North Eastern Africa, Ethnographic Survey of Africa. London: International African Institute, 1995. 
LIMA, Monica. História da África: temas e questões para sala de aula. Cadernos Penesb, n. 7, pp. 68-101, nov. 2006.

LODY, Raul. Cabelos de Axé: identidade e resistência. Rio de Janeiro: SENAC, 2004.

M’BOKOLO, Elikia. África negra história e civilizações até ao século XVIII. Portugal:

Vulgata, 2003.

MÚMIA, O retorno da. Direção: Stephen Sommers. Alphaville Films. Estados Unidos, 2001, $130 \mathrm{~min}$. Son, Color, Formato: $16 \mathrm{~mm}$.

PERDIDA, Os caçadores da arca. Direção: George Lucas. Estados Unidos, 1981. 115 min. Son. Color.

SAGRADA, Bíblia. São Paulo: Stampley Publicações, [1971?].

SALES, José das Candeias. Corpo e tempo: as imagens idealizadas da arte egípcia. digitAR, n. 2, 2015 [online]. Disponível em: <file://C:/Users/Maristane/Downloads/2238-1-7256-210-20150417\%20(2).pdf >. Acessado em: 10 out. 2017.

SYNNOTT, Anthony. Shame and Glory: A Sociology of Hair. British Journal of Anthropology, v. 38, n. 3, pp. 381-413, set. 1987.

TASSIE, Geoffrey John. The Social and Ritual Contextualization of Ancient Egyptian Hair and Hairstyles from the Protodynastic to the End of the Old Kingdom. 2008. Thesis (Doctor of Philosophy) -, Institute of Archeology, University College London, London, 2008.

THOMPSON, Stith. Motif-index of Folk-literature. Indiana: Indiana University Press, 1955 [online]. Disponível em: <https://archive.org/details/B-001-002-578>. Acessado em: $10.10 / 2017$.

WILKINSON, Richard H. Os deuses e deusas completos do antigo Egito. Londres: Tamisa e Hudson, 2003. 